\title{
Currículo prescrito e currículo modelado: uma discussão sobre teoria e prática?
}

\author{
Heloisa Salles Gentil \\ Universidade do Estado de Mato Grosso | Cáceres \\ Claudete Inês Sroczynski \\ Universidade do Estado de Mato Grosso | Sinop
}

\section{Resumo}

Este artigo apresenta discussões sobre concepções de currículo que orientam professores do curso de Pedagogia frente a projetos pedagógicos e práticas formativas, na contingência das políticas educacionais. Esta pesquisa utilizou questionários, análise de documentos, observações participantes e entrevistas. Considera-se que o currículo se constitui em relações sociais e culturais; o currículo real é mais amplo que documentos escritos, é construção social e opera no nível da prescrição e de processo e prática. Conclui-se que há diversos elementos que se tornam preocupações do âmbito educativo, especialmente as relações entre teoria e prática nos processos de formação.

Palavras chave: Currículo. Formação de professores. Teoria e prática.

\section{Prescribed curriculum and modeled curriculum: a discussion of theory and practice?}

\section{Abstract}

This paper presents a discussion about curriculum conceptions that guide teachers in a Pedagogy course against educational projects and teachers education in educational policies. This research has been made using questionnaires, document analysis, observations and interviews. This study consider that the curriculum is constituted in specific social and cultural relations, the actual curriculum is broader than any written document, it is a social construction and it takes place in the level of prescription and in the process and practice. The analysis leads to assert that a lot of factors that become part of education concerns, particularly the relationships between theory and practice in the formation processes.

Keywords: Curriculum. Teachers education. Theory and practice. 


\section{Currículum prescripto y currículum moldeado: una discusión sobre la teoría y la práctica?}

\section{Resumo}

Este artículo presenta discusiones sobre concepciones del currículum que orientan profesores del curso de Pedagogía frente a los proyectos pedagógicos y las prácticas formativas, en la contingencia de las políticas educacionales. Esta investigación utilizó: cuestionarios, análisis de documentos, observaciones participantes y encuestas. Lleva-se en consideración que el currículum está constituido en relaciones sociales y culturales; el currículum real es más amplio que cualquier documento escrito, es una construcción social y opera a nivel de prescripción e en el proceso y en la práctica. Se concluye que hay elementos que se convierten en preocupaciones en el ámbito educativo, especialmente las relaciones entre la teoría y la práctica en los procesos de formación.

Palabras-clave: Currículum. Formación de profesores. Teoría y práctica.

\section{Introdução}

A qualidade na Educação Básica brasileira tem sido temática presente na produção de políticas públicas na área educacional, principalmente a partir da década de 1990, quando foi aprovada a atual Lei de Diretrizes e Bases para a Educação Nacional - LDB 9.394/96, tida como marco desencadeador de reformas educacionais. Tem sido, também, temática de vários estudos, pesquisas, seminários, conferências etc., organizados, promovidos e levados a cabo por instituições educacionais, grupos de pesquisa, pesquisadores, entidades e associações ligadas à área educacional. Mas essa busca por qualidade está imbricada num dos grandes desafios que as instituições de educação superior têm enfrentado: a formação de professores.

Este desafio - formar professores para fazer avançar, qualitativamente, a educação básica - também tem movido a Universidade do Estado de Mato Grosso (UNEMAT), instituição que, em sua origem, em 1978, foi impulsionada pelas licenciaturas, através de cursos regulares e também de programas especialmente criados e desenvolvidos para qualificação de professores em serviço. Esse é um fato que, hoje, a desafia ainda mais, tanto na continuidade dessa políitica - qualificação de professores - avançando inclusive para programas 
de pós-graduação, quanto na avaliação delas, visando à qualidade na formação de professores e, consequentemente, na educação básica.

Oestudo aqui apresentado é um recorte de uma pesquisa mais ampla (Projeto de pesquisa Currículo e Docência no Ensino Superior, uma práxis educativa em construção); situa-se, primeiramente, na proposição de fazer avançar discussões relativas a concepções e perspectivas do professor universitário em relação a sua atuação na formação de professores para a Educação Básica, não só no interior dos Cursos de Pedagogia da UNEMAT, mas também, nas demais licenciaturas, e ainda, na problemática construída no decorrer da pesquisa, orientada pelo seguinte questionamento: como os docentes desta instituição orientam-se frente aos projetos pedagógicos desses cursos e que perspectivas de currículo respaldam suas práticas formativas de professores que atuarão, em sua maioria, na educação básica?

Para tal intento, este estudo parte das concepções de currículo manifestas por professores universitários que atuam em dois cursos de Pedagogia dessa Instituição. Convém observar que a UNEMAT é uma instituição multicampi, portanto os cursos, espaço deste estudo, são ofertados nos Campi de Cáceres e Sinop, localizados a 200 km e 500 km da capital Cuiabá, respectivamente. Embora esses cursos vinculados à mesma Faculdade de Educação e atendam às Diretrizes Curriculares Nacionais e às demais orientações legais, tanto do Conselho Estadual de Educação, como da própria Universidade, possuem projetos pedagógicos distintos.

Assim, contando com a participação direta de dez (10) professores que atuam nesses cursos como sujeitos interlocutores, foi adotada a perspectiva teórico-metodológica amparada na pesquisa participante, que supõe um processo coletivo, no qual os pesquisadores vão construindo os dados "[...] através de sua participação na vida cotidiana do grupo ou organização que estuda" (BECKER, 1997, p. 47).

Essa abordagem, que é dinâmica, comportou reformulações no processo de pesquisa e também, um maior aprofundamento na complexidade do objeto estudado - as concepções sobre currículo entre os professores do curso de Pedagogia - lançando-se mão de vários procedimentos e instrumentos de pesquisa, tais como: questionários, análise de documentos, observações participantes e entrevistas. 
Esses instrumentos - que apontam para opções teóricas e metodológicas, e privilegiam uma abordagem qualitativa - contribuíram tanto para caracterizar o corpo docente pesquisado, quanto para mergulhar na perspectiva prescrita dos currículos dos cursos de Pedagogia, o que permitiu visualizar o entrelaçamento de educação, sociedade e cultura presente nos projetos curriculares. Isso implica dizer que se procurou a construção de conhecimentos através do diálogo e a serviço do diálogo, entre sujeitos diferentes, mas nunca desiguais (BRANDÃO, 2007) situados de um lado e do outro, mas frente a um mesmo horizonte.

No que diz respeito ao sujeito central desta pesquisa, o professor universitário é, aqui, compreendido como um sujeito que participa ativamente na construção e socialização de significados sociais a partir das relações estabelecidas no espaço social chamado universidade. Contudo, não se pode deixar de dizer que essas relações são conflitivas, pois a prática docente que materializa o currículo prescrito é um trabalho interativo e complexo que exige prudência, ética e posicionamento político. Conforme Gauthier (2006, p. 3491, "Ensinar é necessariamente entrar em relação com o outro para transformá-lo, é julgar em contexto, é confrontar-se com o caráter contingente da 52 interação social".

Ou seja, o professor toma decisões, pensa, age em função de certas exigências de racionalidade. "[...] ele dispõe de um poder real, ele julga. Seu julgamento faz a diferença" (GAUTHIER, 2006, p. 349), revelando disputas, contestações e conflitos em relação aos significados sociais que se evidenciam. É nesse trabalho interativo chamado docência que o currículo real é produzido.

E é no vivenciar desse currículo, tal qual aponta Tomaz Tadeu da Silva que os significados sociais "[...] não são simplesmente significados que se situam no nível da consciência pessoal ou individual. Eles estão estreitamente ligados a relações sociais de poder e de desigualdade. Trata-se de significados em disputa, que são impostos, mas também contestados" (SILVA, 1999, p. 55-56).

Na concepção dos professores sujeitos desta pesquisa, conforme verificado durante a investigação, a docência caracteriza-se por elementos como a capacidade de problematizar situações, a inserção nos problemas da comunidade, a disponibilidade de intervir; por princípios de colaboração, de respeito ao outro, pela percepção da possibilidade de conhecimento e 
desenvolvimento contínuo do ser humano; um profissional que saiba fazer a leitura de seu contexto e seja capaz de propor soluções. É na contingência dessas concepções que os professores em foco modelam o currículo dos cursos com os quais trabalham.

Neste estudo, partiu-se do pressuposto de que currículo é algo mais amplo que um conjunto de propostas escritas e constitui-se em determinadas relações sociais e culturais e pode ser pensado a partir das diversas realidades. Porém, não se pode negar que o currículo comumente é tomado a partir de um significado dado a priori que privilegia a organização de um determinado saber no tempo e no espaço "escolar". Essa concepção "simplista" leva a um processo de naturalização desse currículo, como se ele não tivesse história, tampouco fosse fruto das condições de possibilidade do tempo e lugar em que foi organizado como tal, nem expressasse relações de poder. Ou seja, não se pode deixar de ressaltar que suas manifestações escritas, determinações legais, projetos, grades ou matrizes, compõem, apenas, uma das dimensões desse mesmo currículo, pois, como afirma Sacristán (1998, p. 86), "[...] o currículo real é mais amplo que qualquer 'documento' no qual se reflitam os objetivos e planos que temos."

Os professores, ao modelarem um currículo, tomam decisões frente a políticas educacionais e determinações legais que ficam expressas na proposta curricular e orientam, daí por diante, suas práticas cotidianas de ensino em determinado contexto. É como assegura Sacristán (1998): o currículo funciona como uma carta de intenções, nele se pode encontrar concepções que fundamentam a práxis em construção dos professores universitários em sua docência.

Isso evidencia que o currículo é uma construção social que, conforme explicita Goodson (1999, p. 67), de uma forma dialética, opera em dois níveis "[...] primeiramente em nível da própria prescrição, mas depois também em nível de processo e prática." Nessa perspectiva, o currículo, como prescrição, revela um roteiro para legitimar o trabalho docente. Esse roteiro indica o status curricular de determinadas áreas de conhecimento, revela lutas e manifestações em defesa de determinadas áreas, classifica saberes, classifica, de forma oculta, os professores que nele atuam. Já o currículo, em nível de processo e prática, revela saberes e fazeres da docência.

É possível afirmar que projetos pedagógicos constituem materiais importantes que permitem empreender análises acerca do currículo prescrito. 
Este, por sua vez, revela a história também dos cursos, mediante a concepção e organização do conhecimento, do compromisso social e político com a formação de professores e ainda com a formação humana mais ampla, neles manifestos, como demonstrado por Sroczynski e Gentil (2008) ao analisarem um processo de reformulação curricular de um curso de Pedagogia.

É possível afirmar, ainda, que a questão provocadora tem estado presente em diversos outros estudos sobre a formação de professores; destacam-se aqui os estudos de Pimenta (2006) sobre o estágio nos processos de formação. A autora analisa os conceitos de teoria e prática que orientam professores e alunos indagando-se a respeito da unidade entre eles e afirma, a partir do conceito de práxis apresentado por Vázquez, que "[...] na educação, como práxis social, a atividade teórica e prática são indissociáveis" (PIMENTA, 2006, p. 94). É essa a perspectiva que se assume e por meio da qual se busca analisar os dizeres dos professores dos cursos de Pedagogia em pauta.

Para este estudo, são as narrativas de dez professores que fornecem elementos para analisar concepções acerca do currículo, como também conflitos, adesões, perspectivas político-pedagógicas e concepções de sociedade e educação.

período do registro dessas narrativas - 2006/2007 - coincidiu com as discussões e a aprovação das Diretrizes Curriculares Nacionais para o curso de Pedagogia que orientam a organização e estruturação dos projetos pedagógicos desses cursos, que, por sua vez, têm, na Lei de Diretrizes e Bases - LDB n 9.394/1996, sua orientação primeira.

Tais Diretrizes, aprovadas pela Resolução CNE/CP n 1, de 15 de maio de 2006 e Parecer n $n^{\circ}$ /2005, ambos do Conselho Nacional de Educação - CNE, após nove longos anos de discussões constituem concomitante a outros elementos legislativos ${ }^{2}$, uma ampla reforma na organização dos cursos de licenciatura nas Instituições de Ensino Superior Brasileiras. E, apesar do longo período destinado à discussão para a elaboração dessas diretrizes, o documento final gerou, e ainda gera interrogações que ganham contornos específicos a partir dos processos de elaboração dos projetos pedagógicos dos cursos e de seus processos de avaliação, nos quais nem sempre os objetivos, atrelados a um projeto maior de reforma decorrente de políticas públicas para a área educacional, ficam explicitados. 
Observa-se, assim, que, não obstante o debate travado no interior de seus cursos, os professores de Pedagogia dos cursos aqui referenciados, viram-se inseridos num debate mais amplo. Debate este que ganhou qualificação e engajamentos em nível nacional. Estavam diante do desafio de

[...] estabelecer uma formação sólida, com base no conhecimento científico e na pesquisa consolidada, e não ceder à incorporação da racionalidade técnica ou do praticismo pedagógico predominante na epistemologia da reforma educacional oficial, na qual se vincula o conhecimento formativo a uma prática imediatista (SHEIBE, 2007, p. 60).

Neste debate, avoluma-se a pressão para que a instituição universitária renda-se ao mercado de trabalho, bem como suas exigências de formação rápida, o que provoca uma permanente tensão ante a necessidade de se manter os propósitos de formação fundamentados na convicção do que é uma formação universitária de qualidade e que acaba por gerar contradições nas propostas de formação (GENTIL, 2008).

Ainda neste processo tenso, outro aspecto que merece atenção, visto que, traz desdobramentos na consecução do currículo, é a definição legal, porém ampla, do que seja a docência. Ela é

[...] compreendida como ação educativa e processo pedagógico metódico e intencional, construído em relações sociais, étnico-raciais e produtivas, as quais influenciam conceitos, princípios e objetivos da pedagogia. [...] Dessa forma, a docência, tanto em processos educativos escolares como não escolares, não se confunde com a utilização de métodos e técnicas pretensamente pedagógicos, descolados de realidades históricas específicas. Constitui-se na confluência de conhecimentos oriundos de diferentes tradições culturais e das ciências, bem como de valores, posturas e atitudes éticas, de manifestações estéticas, lúdicas, laborais (PARECER CNE/CP N 05/2005, p. 7).

É neste contexto de desafio e reforma e na perspectiva de docência e de currículo acima expressas, que se insere a análise aqui apresentada. Ela está embasada nas narrativas dos dez (10) professores, sujeitos centrais da pesquisa, e tem por objetivo evidenciar posições que possibilitem um entendimento acerca de como esses docentes se orientam diante dos projetos pedagógicos 
dos cursos de Pedagogia nos quais atuam e quais perspectivas de currículo respaldam suas práticas formativas de professores para a educação básica. Para tal intento, abordou-se a trajetória do currículo, do prescrito ao modelado, evidenciando suas tensões e inquietações, o que permite uma leitura desse artefato como processo.

\section{Processos de construção: do currículo prescrito ao currículo modelado}

Independentemente de o professor universitário tomar conhecimento ou não dos dispositivos legais que regulam os cursos superiores, tais como: normatizações, resoluções e/ou projetos curriculares apresentados pelos órgãos e instituições, é preciso que, minimamente, conheça a ementa da disciplina que irá trabalhar, pois ela é o elemento do currículo mais próximo. Entretanto, tal ementa é constitutiva de um projeto pedagógico mais amplo, que configura uma das dimensões prescritivas de currículo que, de certa forma, guia os professores no planejamento das práticas docentes. E, quando eles conhecem ou

56 participam da construção da proposta curricular, sentem-se responsáveis pela sua realização.

Nós, na condição de professores, na posição de professores lá na sala [...] é através das nossas práticas que o currículo, esse currículo, vai se efetivar. Então nós, como professores, temos muita responsabilidade pra fazer valer e acontecer esse novo projeto político pedagógico do curso (P9, 2008).

Neste sentido, o trabalho de planejamento das práticas supõe, necessariamente, que o professor seja um sujeito ativo que, embora observe a prescrição, molda o currículo atribuindo-the significados a partir de seus conhecimentos e de sua formação acadêmica, cultural e social, acrescidos dos significados advindos do contexto institucional e também dos alunos. Portanto, não há neutralidade nesse processo.

As concepções de formação de professores são múltiplas e variam em função de diferentes perspectivas, de diferentes conceitos do que é ser professor. Ora ele é apresentado como educador; ora, como profissional, técnico, prático, competente; ora, ativo, investigador; ora, reflexivo (PIMENTA, 2008), 
ou mesmo por um conjunto de várias dessas características. Essas diferentes concepções sobre quem é ou quem deve ser o professor influenciam de modo determinante os conteúdos, métodos e estratégias escolhidos para o trabalho na formação de professores.

A proposta curricular funciona então como a orientação comum para os participantes de determinado processo de formação. E, nesse sentido, os professores pesquisados ressaltam a importância da ementa do curso como referência inicial em seus trabalhos.

[... não podemos esquecer que o mundo é feito de conteúdo, apesar de muitas discussões pedagógicas em cima da importância do conteúdo, ou da irrelevância de aprofundar, ou de mostrar o quanto de conteúdo tem pra ser trabalhado em sala de aula, eu levo a sério que aquilo que foi colocado na ementa, dentro da minha perspectiva, ele deve ser cumprido ${ }^{3}$. (P5, 2008) $)^{4}$.

Primeiro eu tenho o guia que é o [...] o plano de Curso, né? que é o projeto do Curso. Depois eu tenho as ementas. É esse ementário que me dá o norte [...] (P1, 2008).

A soma dessas duas dimensões (currículo apresentado e modelado), fundamentais na materialização do currículo, permite afirmar, tal qual Sacristán (1998, p. 105), que o professor é "[...] um tradutor, que intervém na configuração dos significados das propostas curriculares." Isso porque a realização das atividades e a concretização dos conteúdos propostos acabam sendo moldadas pelas percepções, pelas opções e estratégias definidas por ele.

Contudo, há que se dizer que esse processo, que vai das ementas à prática docente e que gera o currículo modelado, não é assim tão linear. Revela-se, muitas vezes, tenso e conflitivo e as proposições escritas, tanto em nível mais amplo (políticas públicas), como mais próximo (ementas), levam os professores a expressar inúmeras preocupações:

[... o que nos preocupa hoje dentro deste novo curso é exatamente a abrangência, por que são muitas competências a serem desenvolvidas no formando, no futuro pedagogo, e no espaço de quatro anos eu vejo assim insuficiente para que você possa trabalhar tantas disciplinas relacionadas na formação deste pedagogo, desde a educação infantil, até disciplinas relacionadas às séries iniciais, a legislação da educação, as disciplinas que vão tratar também das questões da gestão (P4, 2007). 
[...] as coisas quando vêm, vêm com muito imediatismo, vem tudo pra ontem, não se faz uma reflexão necessária. [...] esse professor das séries iniciais hoje, acho que é uma questão recente, desafios colocados, desafios novos, como por exemplo, incluir as crianças com necessidades especiais numa mesma sala. Eu acho impossível falar que o nosso curso, numa disciplina de [...] 60 horas vá dar conta (P3, 2007).

Nesse conflito, conforme expressam as narrativas dos professores, o fator tempo assume importância ímpar. Tem sido um dos aspectos questionados por eles em diversos momentos e se torna importante na configuração do currículo modelado. Trata-se de uma formação inicial, porém se percebe que o tempo, seja do curso como um todo ou o de cada disciplina especificamente, quase sempre é tido como aquém da expectativa do professor.

Eu acho impossível falar que o nosso curso, numa disciplina de [...] 60 horas vá dar conta. Aí joga pra formação continuada. Eu fico assim preocupada, porque eu não sei se teríamos um curso capaz de atender... a tantas demandas (P3, 2007).

[...] o que nos preocupa hoje dentro deste novo curso é exatamente a abrangência, por que são muitas competências a serem desenvolvidas no formando, no futuro pedagogo, e no espaço de quatro anos eu vejo assim insuficiente para que você possa trabalhar tantas disciplinas $[\ldots](P 4,2007)$.

Explicita-se um conflito advindo do currículo apresentado ao professor entre ementa e o tempo. Ambos, definidos na construção do projeto pedagógico, no processo de planejamento, desafiam o professor a fazer escolhas, julgar e definir a partir de condições concretas. Ou seja, é o currículo modelado pelo professor que possibilita o equilíbrio entre o projeto pedagógico le aqui se inclui a ementa) e as condições concretas de tempo, espaço e estrutura didático-pedagógica.

Alie-se a isso uma questão relativa ao tempo subjetivo, de amadurecimento de cada estudante que, no período de entrada na universidade, não raras vezes, não sabe bem o que busca profissionalmente. Assim, a relação teoria e prática se apresenta, muitas vezes, como problema de difícil entendimento e de difícil construção de solução para o professor universitário. 
No início do curso, isso não está claro, para os alunos, o que é que eles estão vindo fazer aqui neste curso. Então a disciplina fica mais distanciada ainda, se é o próprio curso que ainda não tem isso. Então como é que você já vai fazer uma proposta de articular teoria e prática se tanto a teoria como a prática estão ainda muito distanciadas. A prática eu, eu coloco assim como se fosse na perspectiva da docência mesmo nas séries iniciais. E a teoria que pudesse fundamentar essa prática, que pudesse fortalecer essa prática (P3, 2007).

[...] a gente acaba enfrentando muita dificuldade dos alunos porque são nos semestres inicias e a carga de leitura é muito grande porque tem muitas disciplinas de fundamento, assim como Psicologia exige leitura, História, Filosofia, Sociologia, vão exigir muita leitura desses alunos e aí a gente esbarra nesse problema da quantidade, do tempo, da dificuldade dos alunos porque é uma grande quantidade de textos e de leitura (P8, 2007).

que se percebe é que essa relação entre teoria e prática - tema recorrente na abordagem dos professores em diversos momentos da pesquisa - está relacionada à forma como percebem a sociedade em que se vive, assim como a um entendimento que os estudos devem servir para uma intervenção prática. Essa relação também revela qual a concepção que se tem de um curso de formação de professores.

Na leitura que os professores fazem da sociedade contemporânea, há visões variadas, mas que se complementam no sentido de apontar diversos aspectos da realidade que os preocupam e se fazem presentes no processo de formação, quer em suas escolhas, opções, propostas e/ou ações. Percebem tanto as desigualdades sociais como as possibilidades (individuais) de contínua mudança dos seres humanos.

Então esta é a visão de sociedade que eu tenho que é uma sociedade muito desigual, mas a principal divisão dela é de classe. Aí a questão de gênero, sexo, idade, filhos etc. elas são mais pontuais elas só reforçam esta visão classista (P1, 2008).

[...] tento ter uma visão humanista do ser humano, ou seja, ninguém nasceu para pagar pecado, ninguém nasceu para... é... expiar alguma coisa. As pessoas têm que ter oportunidades. E destas oportunidades é que ele constrói o caminho dele. Então a visão que eu tenho de ser humano é sempre alguém em construção. Idealmente seria em cima de condições boas. Mas como não é, 
tem que ser um ser humano sabendo destas condições para poder superar as dificuldades e contradições (P1, 2008).

Muitas vezes, o entendimento dos próprios professores sobre a relação teoria/prática está vinculado apenas à relação entre o que os estudos já fundamentados (de caráter científico) propõem e o que o fazer cotidiano realiza, no entanto não chegam a considerar a práxis, esse fazer e pensar que modifica o meio pela ação do homem e também o próprio homem. Pimenta (2006, p. 86) se apoia em Marx ao reafirmar que "práxis é atitude (teórico prática) humana de transformação da natureza e da sociedade. Não basta conhecer e interpretar o mundo (teórico), é preciso transformá-lo (práxis). Mas, entre os professores, há aqueles que identificam esse processo dialético, de mudança, presente no desenvolvimento humano e, portanto, na relação teoria/prática:

Então a gente parte do pressuposto que todo ser humano pode mudar, a psicologia vai dizer, o ser humano quando muda suas estruturas cognitivas, a gente diz, muda sua forma de pensar, ao mudar sua forma de pensar, ele muda sua forma de se relacionar (P8, 2007).

60 Neste sentido, a percepção de uma sociedade desigual e cheia de contradições orienta o olhar dos professores sobre diversas questões atinentes às discussões atuais na área educacional, como as duas posições destacadas a seguir:

Atualmente, preocupada com essa questão cultural, eu preocupo com um ser humano que reconheça a alteridade que reconheça a diferença, que reconheça que [...] além de nós termos uma sociedade desigual no plano econômico, injusta, excludente, nós também, temos também uma sociedade que trata iguais de uma maneira desigual (P3, 2007).

Nós temos muitos problemas na sociedade hoje, onde não existe o respeito ao outro porque cada um se individualiza na profissão que vai ter, no fazer que vai ter e [...] se ele conseguir se entender como um todo e ter esta relação afetiva com ele e com o outro, a sociedade que nós vamos ter também vai ser é uma sociedade mais alegre, uma sociedade melhor e sem problemas (P6, 2008). 
Os depoimentos seguintes, também relacionados à sociedade, apontam para outro problema percebido em suas relações com a profissão professor: a questão dos valores, o respeito ao outro, as diferenças, os sentimentos:

Eu sempre sou muito [...] no sentido do humanismo, da sinceridade, da lealdade, no sentido da lealdade assim de não ferir o outro, de procurar nunca passar por cima do outro. E é isto que eu tento trabalhar com os alunos (P7, 2008).

[É preciso] uma sensibilidade maior do ser humano que está aí porque cada vez mais eu vejo um ser humano nessa sociedade perdido, desorientado, sem chão, porque se perderam muitos valores na atualidade. Temos mentes vazias, corações vazios e toda outra sorte de [...] comportamentos que você vê aí (P3, 2007).

[...] eu me preocupo com a formação dele enquanto um ser humano, enquanto profissional então eu trabalho [...] aproveito pra trabalhar todos os conteúdos inclusive os valores sociais e humanos, que a gente [...] eu falo: você é o futuro, você é [...] vai atuar em sala de aula, você vai ser um professor/uma professora e você antes de tudo é uma pessoa então você tem que primeiro pensar na sua formação enquanto pessoa para depois pensar na sua formação enquanto profissional (P9, 2008).

Segundo Sacristán (1998), há um conjunto de elementos que influenciam e são influenciados pelas práticas dos professores, desde a definição de políticas educacionais, passando pelas diretrizes da instituição em que atua, pelas relações entre pares e outros envolvidos no processo educacional, até a sua experiência e visão em relação tanto ao curso como à disciplina específica com a qual trabalha. Deste modo, as questões sociais vão sendo entremeadas ao currículo em sua modelagem. É como afirmam também Jesus, Cerezer e Ribeiro (2007, p. 23):

Nesse contexto histórico social, a profissão docente enfrenta desafios que transformam o campo de atuação profissional numa arena de conflitos, incertezas, angústias, insatisfações e outros problemas de origens diversas. É nessa realidade conturbada que o professor terá que desenvolver sua prática pedagógica e o grande desafio que se apresenta é como lidar com tamanha diversidade de situações e problemas singulares para os quais não se tem uma resposta ou solução definida a priori. Nesse contexto de situações problemáticas e incertas, para as quais a solução não está de forma explícita nos livros e teorias estudadas. 
Ou seja, tais concepções interferem, sobremaneira, na efetivação do currículo, desde o planejamento até a execução, ou seja, no currículo em ação. Ao serem indagados sobre o currículo, a ementa aparece nas narrativas dos professores, como já se destacou anteriormente, como primeiro elemento norteador do planejamento, seguida pela impressão que se tem a respeito da turma com a qual se vai trabalhar; uma demonstração de atenção à especificidade do grupo de alunos. Além disso, há também a preocupação com o contexto histórico do conhecimento a ser abordado em suas diversas perspectivas e sua relação com a vida, com a prática.

Os professores citam leitura (destacando sempre as dificuldades dos alunos), aula expositiva dialogada, uso de filmes e pesquisa de campo como estratégias para atingirem seus objetivos no processo de ensino e aprendizagem. Para os professores interlocutores deste estudo, planejar, mesmo a partir de ementas e planos de curso, ou seja, do currículo prescrito, é um processo de escolha, de seleção e cada um deve assumir sua parte nesse processo. Nessa autoconsciência de suas responsabilidades como professor, vislumbra-se a necessidade de uma prática docente explicitada como interdisciplinar.

Em relação a essa perspectiva interdisciplinar Santomé (1998), em 62 seu trabalho acerca da interdisciplinaridade do conhecimento, argumenta que

A interdisciplinaridade é um objetivo nunca completamente alcançado e por isso deve ser permanentemente buscado. Não é apenas uma proposta teórica, mas sobretudo uma prática. Sua perfectibilidade é realizada na prática; na medida em que são feitas experiências reais de trabalho em equipe, exercitam-se suas possibilidades, problemas e limitações. É uma condição necessária para a pesquisa e a criação de modelos mais explicativos desta realidade tão complexa e difícil de abranger (SANTOMÉ, 1998, p. 66-67).

Ou seja, um trabalho interdisciplinar vai exigir que professores assumam tanto o desafio da busca contínua por tal perspectiva quanto a difícil tarefa de formar professores numa realidade social, econômica e cultural complexa.

Um dos entrevistados faz um alerta sobre essa necessidade de trabaIhos interdisciplinares ou, no mínimo, de cooperação entre docentes de áreas diferentes para "dar conta" de determinados aspectos da formação, incluindo 
aí as relações entre teoria e prática. Reforça a ideia da necessidade de trabatho interdisciplinar ao explicar a proposta de funcionamento do estágio.

[...] o professor precisa ter esta visão multilateral, este professor não pode ter esta visão estreita da sua área de conhecimento, mas ele precisa inter-relacionar. Então, o interdisciplinar é uma nova forma de apreensão do conhecimento onde que dado objeto é analisado em todas as suas inter-relações, então a gente busca fazer do estágio interdisciplinar uma forma em que o estagiário passa a compreender a constituição da escola enquanto um objeto constituído por múltiplos elementos que interferem ali. Então o estágio tem exatamente esta dimensão, de fazer com que o estagiário compreenda como é que a escola se constitui enquanto um espaço de construção de conhecimento (P4, 2007).

A interdisciplinaridade, tida como possibilidade de rompimento das fronteiras disciplinares e do mero acúmulo de informações, ainda se situa no campo das possibilidades. Há projetos para tal, mas a materialização não tem se dado como prevista. Ainda é uma prática incipiente. E, conforme destaca um dos entrevistados, ainda predomina o trabalho individualizado:

Enquanto referencial teórico, o que a gente percebe assim que não é feito num planejamento interdisciplinar, assim entre os professores, isso não é feito de forma objetiva, com finalidade, o que a gente percebe é que quando você vai falar alguma coisa, retomando alguma coisa o aluno diz 'Ah, a professora de sociologia já falou disso, iá tocou nisso, a professora de história [...]' (P8, 2007).

As falas apontam, sobretudo, para a falta de uma atuação coletiva de professores. E, como afirma Sacristán (1 998), é essencial, para o desenvolvimento de um currículo de formação docente, a existência de uma visão coletiva dos formadores sobre essa formação.

Já no que diz respeito à estrutura formal dos cursos de Pedagogia, cujo referencial basilar são as Diretrizes Curriculares, há ênfase em uma perspectiva de trabalho coletivo que visa, em última instância, superar o isolamento constatado no cotidiano pedagógico. Tais Diretrizes trazem uma concepção ampla de docência, conforme já referenciado anteriormente, e indicam uma estrutura para sua organização. 
Os núcleos que definirão a estrutura do curso de pedagogia - núcleo de estudos básicos; núcleo de aprofundamento e diversificação de estudos; núcleo de estudos integradores - devem se integrar e articular ao longo de toda a formação, a partir do diálogo entre os diferentes componentes curriculares, por meio do trabalho coletivo sustentado no princípio interdisciplinar dos diferentes campos científicos e saberes que informam o campo da pedagogia (AGUIAR; BRZEZINSKI; FREITAS; SILVA; PINO, 2006, p. 833).

Nessa proposição de estrutura, os professores que atuam em disciplinas que fazem parte do Núcleo de Estudos Básicos, também conhecido como Fundamentos, têm uma posição definida bastante clara acerca da função da disciplina que lecionam em relação à formação almejada ao futuro professor:

Metodologia de Pesquisa: [...] fazer com que os professores adquiram a técnica e a prática de no seu cotidiano de aula buscar uma problematização daí leva a uma teorização para poder dar respostas mais refinadas do que as do senso comum (P1, 2008).

Psicologia: [...] a psicologia, ela entra como disciplina ponte que vai trazer alguma coisa da natureza humana para a área da educação. [...] Não vai dar respostas, né? É [...] não vai trazer fórmulas pra resolver os problemas, mas ter o conhecimento, os referenciais podem contribuir para a formação do professor lá na frente na sua prática (P8, 2007).

Sociologia: [...] despertamos [...] conceitualmente, a eles trabaIharem em grupos, que é um dos conceitos bastante utilizados em Sociologia, [...] mas existem conceitos que a gente trabalha em sala de aula e que todos estes conceitos na medida do possível eu procuro trazer para a realidade. Então, se esta realidade ela [...] é possível ser percebida por este acadêmico, eu acredito que há uma outra postura, vai ser uma interação de fato da Disciplina com a carreira (P5, 2008).

Em síntese, o Núcleo de Estudos Básicos traz, para si, o papel de problematizar a realidade e contribuir com um referencial que possibilite análise e intervenção de caráter profissional, o que pode ser percebido quando os entrevistados se referem ao cotidiano do professor, à sua prática, à sua carreira como espaços significantes para a aprendizagem obtida no curso. 
A atividade teórica é que possibilita de modo indissociável o conhecimento da realidade e o estabelecimento de finalidades para sua transformação. Mas para produzir tal transformação não é suficiente a atividade teórica; é preciso atuar praticamente (PIMENTA, 2006, p. 921.

Já nas disciplinas que se referem ao Núcleo de Estudos Integradores, há uma concordância de que elas têm essa função - integrar - bem definida. Ou seja, configuram um espaço teórico-prático de reflexões e ações, no qual as outras disciplinas "aparecem" de acordo com as necessidades advindas das ações desenvolvidas.

Prática Pedagógica: - A preocupação dela é articular teoria e prática. [...] A prática eu, eu coloco assim como se fosse na perspectiva da docência mesmo nas séries iniciais. E a teoria que pudesse fundamentar essa prática, que pudesse fortalecer essa prática. [...] ela foi pensada para vir início do curso a partir do segundo semestre, ela já veio pensada como uma proposta de trabalho coletivo, então eu não me angustio sozinha, tem um grupo de colegas, né? Que partilham comigo isso: o que nós poderíamos fazer? Os professores que trabalham a fundamentação necessária para olhar a escola e a relação necessária dela com a sociedade e um projeto político maior de formação se sujeitos [...] não existe uma prática sem uma sustentação teórica de base e não existe uma teoria que não nasça de uma reflexão sobre a prática (P3, 2007).

Estágio Supervisionado: [...] muitos pensam que é uma disciplina prática, mas não. Ela é uma disciplina teórico-prática que visa exatamente fazer esta interlocução, ou esta aproximação do futuro profissional - docente com o seu campo de trabalho, que é a escola. Então a nossa disciplina tem essa função de constituir este novo docente na situação real de trabalho (P4, 2007).

Estágio Supervisionado: [...] é um dos momentos em que ele faz um resgate de todos os conteúdos e teorias que ele tem, vem estudando ao longo do curso e aí ele busca a filosofia, busca a sociologia, busca a história, quer dizer é uma série de áreas de conhecimento pra ele compreender aquela dada realidade [...] (P4, 2007).

terceiro Núcleo, por sua vez, constitui-se no Aprofundamento e Diversificação de Estudos e deve estar voltado às áreas de atuação do pedagogo, em observância às demandas sociais e institucionais, a fim de possibilitar 
processos de investigação dos espaços e situações educacionais, tanto formais como não formais, e desafiar para estudos, análises e inovações.

Educação Física: - Para que de alguma forma os professores que concluírem o curso estejam preparados para conseguir lidar com esta criança. Que esta criança quer mobilidade, que não é uma criança sem corpo. [...] os futuros professores pedagogos é que eles valorizem a parte corpórea da criança, e consigam fazer com que tanto a parte corpórea quanto a parte emocional afetiva e a cognitiva formem um único ser (P6, 2008).

Língua Portuguesa para o início da escolarização: [...] contribui para a formação desse futuro pedagogo, no sentido de que ele vai [...] construir uma concepção do ensino da linguagem [...] a linguagem ela tudo, [...] ela é a mediação necessária entre o homem e a realidade natural e social. Então é nessa perspectiva que eu contribuo com os meus alunos para que ele vá lá e faça um trabalho com os seus alunos a partir dessa concepção (PQ, 2008).

Neste sentido, o que se observa é que há um distanciamento da proposição expressa nas Diretrizes Curriculares e no entendimento dos profes66 sores, que ainda está bastante centrado em uma única instituição educacional, a escola.

Apesar das diferentes disciplinas e das funções a elas atribuídas pelos professores, explicita-se, em todas as falas, a preocupação com a relação teoria e prática. Há uma busca constante de relacionar o conteúdo trabalhado em cada disciplina à realidade, ao contexto em que ocorrem as práticas docentes. Os entrevistados percebem a necessidade de a formação na graduação oferecer elementos para a prática educativa no contexto da sociedade atual, isto é, percebem a importância de prepará-los para uma prática relacional, comprometida, de caráter histórico. Veiga (2002), analisando essa questão em seus estudos a respeito do estágio na formação de professores, afirma a unicidade entre teoria e prática.

Isso significa que a relação teoria/prática perpassa todo o processo de formação e não apenas a prática de ensino em uma visão finalística. A formação tem como fundamento básico o trabalho como princípio educativo e a pesquisa como meio de produção de conhecimento e intervenção na prática social e especificamente na prática pedagógica (VEIGA, 2002, p. 83-84). 
Esse é um ponto muito debatido e sempre presente na discussão da formação de professores: teoria e prática. São aspectos distintos, opostos ou complementares? De que modo deveriam ser abordados no processo formativo? Como os alunos percebem essa relação? Segundo Ramalho, Núñez, e Gauthier (2004):

[...] a teoria desempenha um papel essencial na sua relação dialética com a prática, sendo mais produtiva na medida em que se orienta em novas referencias teóricas do saber científico e de outras formas de saberes, na medida em que se realiza com métodos sistematizados (atitude de pesquisa) que levam a uma posição crítica da prática em questão (RAMALHO; NÚÑ̃EZ e GAUTHIER, 2004, p. 26).

A preocupação, advinda dessa relação teoria e prática, que os projetos curriculares, na sua maioria, não conseguem minimizar, produz um conflito constante entre o currículo modelado pelo professor e o currículo em ação. Esse conflito desafia os professores, faz com que busquem esclarecer esse jogo dialético, mas, ao explicitarem suas concepções o que se evidencia é uma perspectiva de complementaridade e não uma ideia de contradições que possam ser superadas. É como se a teoria complementasse ou somasse com a prática.

Metodologia: [... ] então a questão que eu penso é o aluno na prática e a teoria. Então se é comum ouvir os acadêmicos dizerem que a teoria é diferente da prática, então eu tento fazer esta conciliação na hora da fala, da discussão [...] naquele momento, que vem a questão teórica, [se] eu não consigo trabalhar, mas eu peço que eles abordem isto com os professores das metodologias [...] (P7, 2008).

Estágio: [...] aquele real constituído que no caso é a nossa escola née o cotidiano escolar, para depois dessa leitura, dessa interpretação ele poder pensar na posição de estagiário, na posição de um professor na época do estágio do ensino fundamental [...] ele pode então preparar o seu plano de aula porque ele já conheceu e já interpretou, aí ele vai para a intervenção. [...] tentando sempre, sempre articular teoria e prática, fazer a relação, reflexão, ação, nós contribuímos com este olhar diferente (P4, 2007). 
A visão que se tem do processo dialético do encontro teoria/prática acaba por subtrair aquilo que the é mais caro, o seu caráter contraditório. Nesse sentido, o resultado não é uma soma, mas sim, o surgimento de uma nova prática que, por sua vez, permite a construção de uma nova teoria, negando o caráter estático do conhecimento, muitas vezes, "naturalizado" no currículo prescrito. Uma visão superficial do que seria a relação teoria/prática leva à simplificação, muitas vezes, expressa, de que teoria é tudo o que se escreve e prática é o que se faz. Essa perspectiva fragmenta, separa teoria e prática, dando a essa última um caráter pragmático, utilitarista como na percepção do senso comum.

Cabe ressaltar que não é essa a compreensão adotada para essa análise. Entende-se essa relação na perspectiva dialética da práxis, conforme explica Vázquez (2007): uma atividade consciente, objetiva, sem caráter estritamente utilitário, cuja consciência está além do senso comum, o ultrapassa, pois é capaz de perceber a transformação da natureza e do humano na e a partir da ação, do trabalho.

\section{Compreendendo o currículo como processo}

Numa relação que é dialética em sua natureza, as atuais políticas educacionais e as reflexões dos professores sobre as práticas docentes de formação têm levado os profissionais do ensino superior a sistematizar e concretizar em forma de projetos políticos pedagógicos suas expectativas e propostas de formação. Para tal empreendimento, cada vez mais fica patente a necessidade de clareza de concepções tanto de formação professores como de currículo. São dois pressupostos para qualquer proposição no sentido de inovações, especialmente quando se trata da formação de professores.

Acredita-se que o estudo empreendido e aqui relatado, buscando compreender como os docentes dos dois cursos de Pedagogia da UNEMAT se orientam diante dos projetos pedagógicos e que perspectivas de currículo respaldam suas práticas docentes é representativo, pois, embora os dados refiram-se a um grupo pequeno de professores, sinalizam tensões e inquietações em relação a questões atuais presentes nas discussões acerca de currículo e formação. 
Assim, retomando o que já foi apresentado, os dois cursos passaram por mudanças em seus currículos, processo durante o qual o coletivo de professores se reuniu e discutiu sobre o curso, as áreas, as disciplinas, a legislação em vigor, o perfil do profissional que se deseja formar e o perfil do aluno real que chega à universidade. Tanto em um como em outro curso, entre os professores entrevistados, todos já possuem experiência de docência, portanto esse período de elaboração ou re-elaboração da matriz curricular pode ser considerado um processo de reflexão sobre a ação e de reflexão sobre a reflexão na ação. As propostas curriculares reelaboradas, atualmente já em desenvolvimento nos cursos, preveem articulação entre as disciplinas e as áreas e também a pesquisa como um elemento fundante do processo contínuo de aprendizagem, característico da profissão professor.

É preciso considerar também que, mesmo os novos currículos, elaborados após as Diretrizes, contêm contradições, não se apresentam fundamentados numa perspectiva explícita de conhecimento; ora se sustentam em noções típicas da racionalidade técnica, tal como expresso nas ideias de habilidades e competências, voltadas à atuação do professor no ensino fundamental; ora se pautam na racionalidade prática, vinculando o saber à realidade e enfatizando a pesquisa e a reflexão sobre a prática (GENTIL, 2008). Popkewitz lapud KRAHE, 2007) já afirmava estarmos em momento de transição quando podemos encontrar nos programas de formação de professores as duas racionalidades (técnico instrumental e prático reflexiva) em interação e foi o que constatamos em nossas análises.

Assim, pode-se afirmar que os professores, sujeitos ativos em todo esse processo, se apresentam em suas respostas à entrevista, como em período de transição:

a) demonstram preocupação com os sujeitos em formação e o contexto em que se inserem e no qual vão atuar como profissionais;

b) reconhecem a teoria como elemento indissociável da prática;

c) afirmam seus propósitos de possibilitar um conhecimento articulado com a prática, promovendo o desenvolvimento de atividades com esse fim em suas disciplinas específicas;

d) manifestam a importância do trabalho coletivo e da interdisciplinaridade. 
No entanto, no relato sobre o planejamento e a realização das atividades de suas disciplinas, as experiências de trabalho coletivo e interdisciplinar são citadas como ações "tímidas" e pouco generalizadas, embora definidas como horizonte nas matrizes curriculares dos cursos.

Entre os entrevistados, predomina uma visão otimista, haja vista a reforma curricular de ambos os cursos e a concepção, dominante entre os professores sujeitos desta pesquisa, de que o currículo prescrito e apresentado é um guia para seu trabalho, inclusive porque eles mesmos colaboraram em sua proposição (currículo modelado). Afirmam que as novas propostas curriculares ampliam os horizontes, possibilitam um trabalho mais completo de formação, "dão mais conta" da realidade na qual o profissional vai atuar, instrumentalizam o futuro professor para as práticas que terá que desenvolver. No entanto, há ressalvas quanto ao fator tempo para a realização dos objetivos propostos, pois é tido como insuficiente em relação a uma concepção tão ampla de docência, o que pode comprometer sua efetivação.

A preocupação com a relação entre teoria e prática é o elemento comum entre todos os professores ao refletir sobre o currículo em questão e as disciplinas que lecionam. Os depoimentos apresentam não só as preo70 cupações como também as diversas propostas de atividades e expectativas com a prática docente dos futuros profissionais. $\bigcirc$ conflito dialético, que é tenso, porém configurador de novas práticas, apresenta-se de forma confusa nos relatos; mais como angústias de caráter solitário, que colocam em xeque o potencial criador, que como um elemento que problematiza a realidade e convida à sua superação.

Mais uma vez, concorda-se com Pimenta quando afirma que:

currículo do curso no seu todo (disciplinas e atividades) precisa captar na práxis existente os conflitos, os confrontos, os pontos de resistência, as possibilidades de avanço, enfim, a contradição. [...] A contradição aponta não só o que pode ser mudado, mas também para onde o que está mudando pode ser direcionado (2006, p. 184).

Por vezes, há uma tendência à simplificação no sentido de encarar a proposta curricular escrita como "teoria" e as ações pedagógicas como "prática", mascarando a relação dialética existente entre ambas e, inclusive, reforçando a ideia predominante no senso comum de que o ensino superior 
é, apenas, teórico e, por isso não traz os efeitos esperados à educação em geral. É importante recorrer a Vázquez (2007), para quem a superação do "senso comum" não ocorre de forma espontânea, exige deliberação, requer uma atitude filosófica de reflexão. Em se tratando de professores, pode-se dizer que isso ocorre quando eles assumem seu lugar de intelectuais, capazes de compreender a produção humana de significados, ultrapassando a visão pragmática e utilitária de prática e, dessa forma, percebendo as transformações que o homem, por meio de seu trabalho, provoca na realidade ao mesmo tempo que transforma a si mesmo. A "passagem" do currículo prescrito ao currículo modelado e ao currículo em ação constitui momentos e espaços importantes para essa atitude, para essa reflexão. São expressões da relação dialética, e, por isso mesmo, conflituosa, entre teoria e prática.

Tudo isso permite considerar que é sempre necessária uma atenção especial aos currículos e seus processos de construção, desde sua prescrição até sua efetivação, passando pela modelagem feita pelos professores. Nem sequer uma política pública bem delineada de formação de professores é capaz de explicitar a forma concreta como as práticas formativas se darão, visto que são numerosos os fatores que determinam um currículo real. $E$, nesse sentido, é preciso compreendê-lo, dialeticamente, para interferir em seu processo, considerando o movimento entre teoria e prática com suas inerentes contradições.

\section{Notas}

1 Essa discussão foi, inicialmente, registrada nos anais da ANPEd, 2009, tendo sido revista e ampliada para este artigo.

2 Resolução CNE/CP n. 1/2002 que institui as Diretrizes Curriculares Nacionais para a Formação de Professores para a Educação Básica.

3 Resolução CNE/CP n. 2/2002 que institui a duração e a carga horária dos cursos de licenciatura.

4 Todos os grifos nas narrativas dos sujeitos interlocutores são das autoras.

5 Os interlocutores (sujeitos pesquisados) são identificados como P1, P2, P3. 


\section{Referências}

AGUIAR, Márcia Ângela da Silva; BRZEZINSKI, Iria; FREITAS, Helena Costa; SIIVA, Marcelo Soares Pereira da; PINO, Ivany Rodrigues. Diretrizes curriculares do curso de pedagogia no Brasil: disputas de projetos no campo da formação do profissional da educação. Educação \& Sociedade, Campinas, v. 27, n. 96, p. 819-842, out. 2006. Disponível em: <http:// www.cedes.unicamp.br>. Acesso em: 20 nov. 2008. (Especial).

BECKER, Howard. Métodos de pesquisa em ciências sociais. 3. ed. Hucitec: São Paulo, 1997.

BRANDÃO, Carlos Rodrigues. A pesquisa participante na docência a busca do diálogo na construção do saber. Escritos abreviados, 2007. Disponível em: <http://www.pde.pr.gov. br>. Acesso em: 23 jun. 2008. (Série pesquisa).

BRASIL, Conselho Nacional de Educação. Parecer CNE/CP n 05 de 13 de dezembro de 2005, p. 7.

GAUTHIER, Clermont; MALO, Annie; SIMARD, Denis; DESBIENS, Jean-François; MARTINEAU, Stéphane. Por uma teoria da pedagogia: pesquisas contemporâneas sobre o saber docente.

2. ed. ljuí: Editora UNIJUÍ, 2006.

GENTIL, Heloisa Salles. Proposta curricular de formação de professores em tempos neoliberais, espaço de contradições. In: ASSOCIAÇÃO NACIONAL DE PÓS-GRADUAÇÃO E PESQUISA EM EDUCAÇÃO | ANPEd, 31 ., 2008, Brasília. Anais... Brasília: ANPEd Centro Oeste, 2008. p. 44-57.

GOODSON, Ivor. Currículo: teoria e história. 3. ed. Petrópolis : Vozes, 1999.

Currículo, narrativa e o futuro social. [online]. Revista Brasileira de Educação, Rio de Janeiro, 12, n. 35, p. 241-252, maio/ago. 2007.

JESUS, Nauk Maria de; CEREZER, Osvaldo Mariotto; RIBEIRO, Renilson Rosa (Org.). Ensino de história: trajetórias em movimento. Cáceres: UNEMAT, 2007.

KRAHE, Elizabeth Diefenthaeler. Sete décadas de tradição ou a difícil mudança de racionalidade da pedagogia universitária nos currículos de formação de professores. In: FRANCO, Maria Estela Dal Pai; KRAHE, Elizabeth D. (Org.). Pedagogia universitária e áreas de conhecimento. Porto Alegre: EdPUCRS, 2007.

P1. Entrevista. Sinop, 28 fev. 2008. 
P3. Entrevista. Cáceres, 19 out. 2007.

P4. Entrevista. Cáceres, 21 set. 2007

P5. Entrevista. Sinop, 24 jan. 2008.

P6. Entrevista. Sinop, 24 jan. 2008.

P7. Entrevista. Sinop, 25 jan. 2008.

P8. Entrevista. Cáceres, 26 set. 2007.

P9. Entrevista. Sinop, 27 mar. 2008.

PIMENTA, Selma Garrido. O estágio na formação professores: unidade teoria e prática? 7. ed. São Paulo: Cortez, 2006.

PIMENTA, Selma Garrido e ANASTASIOU, Léa das Graças Camargos. Docência no ensino superior. 3. ed. São Paulo: Cortez, 2008.

RAMALHO, Betânia Leite; NUÑEZ, Isauro Beltán; GAUTHIER, Clermont. Formar o professor, profissionalizar o ensino: perspectivas e desafios. 2. ed. Porto Alegre: Sulina, 2004.

SACRISTÁN, Jose Gimeno; GÓMEZ, Angel Pérez. Compreender e transformar o ensino. 4. ed. Porto Alegre: Artmed, 1998.

O currículo. 3. ed. Porto Alegre: ArtMed, 2000.

SANTOMÉ, Jurjo Torres. Globalização e interdisciplinaridade: o currículo integrado. Porto Alegre: Artmed, 1998.

SCHEIBE, Leda. Diretrizes curriculares para o curso de pedagogia: trajetória longa e inconclusa. Cadernos de Pesquisa. São Paulo, v. 37, n. 130, p. 43-62, jan./abr. 2007.

SILVA, Tomaz Tadeu da. Documentos de identidade: uma introdução às teorias do currículo. Belo Horizonte: Autêntica, 1999.

SROCZYNSKI, Claudete Inês; GENTIL, Heloisa Salles. Reflexões sobre o processo de (des) construção e inovação do currículo de um curso de Pedagogia. COLÓQUIO LUSO BRASILEIRO SOBRE QUESTÕES CURRICULARES. 4., 2008, Florianópolis. Anais. Florianópolis: Universidade Federal de Santa Catarina. 2008. p. 1-19.

VEIGA, Ilma Passos Alencastro; AMARAL, Ana Lúcia (Org.). Formação de professores: políticas e debates. Campinas: Papirus, 2002.

VÁZQUEZ, Adolfo Sánchez. Filosofia da práxis. São Paulo: Expressão Popular, 2007. 
Artigo

Currículo prescrito e currículo modelado: uma discussão sobre teoria e prática?

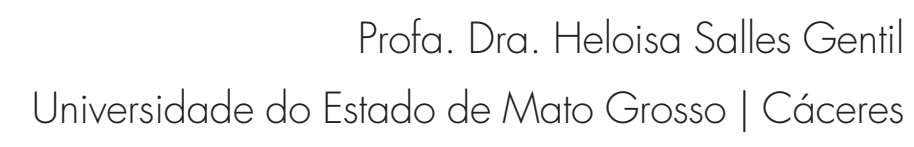

Departamento de Pedagogia

Grupo de Pesquisa Currículo e Docência no Ensino superior

E-mail | logentil@uol.com.br

Profa. Ms Claudete Inês Sroczynski

Universidade do Estado de Mato Grosso | Sinop

Departamento de Pedagogia

Grupo de Pesquisa Currículo e Docência no Ensino superior

E-mail | claudete_ski@hotmail.com

Recebido 26 maio 2014

Aceito 09 jun. 2014 